\title{
A LEGISLAÇÃO DO FUNDEB
}

\section{PAULO SENA}

Doutorando pela Faculdade de Educação da Universidade de Brasília

Programa de Políticas Públicas e Gestão da Educação

Consultor Legislativo - Área de Educação, Cultura e Desporto da Câmara dos Deputados paulo.martins@camara.gov.br

\section{RESUMO}

O artigo analisa a legislação referente ao Fundo de Manutenção e Desenvolvimento da Educação Básica e de Valorização dos Profissionais da Educação - Fundeb -, em contraste com as normas do Fundo de Manutenção e Desenvolvimento do Ensino Fundamental e de Valorização do Magistério Fundef. Identifica e discute: as características do novo fundo, que já integravam o fundo precedente; os aperfeiçoamentos em relação à legislação do Fundefe as opções técnicas distintas. Aponta os aspectos problemáticos da nova legislação, como a aplicação indistinta dos recursos entre as etapas e modalidades de ensino e os tipos de estabelecimento, independentemente de seu peso para a captação dos recursos, bem como a inclusão das matrículas privadas da educação especial e das creches de forma permanente, para além, portanto, de um prazo de transição. Propõe que a participação da União no financiamento da educação retome o patamar de 1995, em termos de percentual de gastos por esfera federativa.

FINANCIAMENTOS DA EDUCAÇÃO - POLÍTICAS PÚBLICAS - LEGISLAÇÃO DO ENSINO

\section{ABSTRACT}

FUNDEB'S LEGISLATION. This paper analyses the legislation concerning the Fund for the Maintenance and Development of Basic Education and Educational Professionals Valorization, contrasting it with that about the Fund for the Maintenance and Development of Fundamental Education and Teacher Valorization. It identifies and discusses: the characteristics of the new Fund that were already present in the previous one, the improvements acquired in contrast to Fundef and the different technical choices. The study also indicate the problematic aspects of the new legislation, such as: a) the indistinct use of the financial resources among levels and modalities of instruction, schools, and teaching settings, independently of their respective weight in the collection of resources; b) the inclusion special education private enrollments and those of day care centers in a permanent way, without considering a transitory period. The paper proposes that the financial contribution of the Union to education come back to 1995's level, in terms of the percentage of expenditures by federative sphere.

EDUCATIONAL FINANCES - PUBLICS POLICIES - EDUCATIONAL LEGISLATION 
O Fundo de Manutenção e Desenvolvimento do Ensino Fundamental e de Valorização do Magistério - Fundef - foi substituído pelo Fundo de Manutenção e Desenvolvimento da Educação Básica e de Valorização dos Profissionais da Educação - Fundeb - em 2007, após dez anos de vigência e nove de implantação em nível nacional'.

Consoante diretriz do Plano Nacional de Educação - PNE -, manteve-se o financiamento da educação por meio de fundos de natureza contábil com contas específicas (Brasil, 2002).

A experiência do Fundef e o aprendizado que este possibilitou trouxeram a reflexão acerca de quais elementos deste mecanismo deveriam ser preservados ou evitados no novo fundo.

Entre os avanços significativos do novo fundo figura, em primeiro lugar, a abrangência da forma pela qual todas as etapas da educação básica passam a contar com um mecanismo de financiamento, bem como o encaminhamento satisfatório, como ponto de partida, da questão da participação financeira da União. No período de vigência do Fundef, o (legítimo) papel exercido pela União, de coordenação federativa da política pública para o financiamento da educação, fez-se com o sacrifício (ilegítimo) de seu necessário papel de exercício da função supletiva, o de proporcionar o aumento dos recursos disponíveis por aluno/ano, o que teria impacto positivo sobre a qualidade, mas principalmente sobre a redução das desigualdades regionais. Os governos do período omitiram-se em relação ao pacto federativo, que carece da reconstrução no setor educacional. A Legislação do Fundeb - Emenda Constitucional - EC n. 53/06 e a Lei do Fundeb - Lei n. I I.494/07 parecem contribuir para esse objetivo, na medida em que:

a. foi constitucionalizada a regra de contribuição da União, via complementação ao Fundeb, e se definiu um patamar mínimo de alocação de recursos federais (10\% do valor dos fundos), com a proteção de algumas fontes, de modo a trazer efetivamente recursos novos. Trata-se de avanço significativo, adequado ao federalismo cooperativo e que terá resultados concretos no que se refere à diminuição das desigualdades regionais;

I. Apenas o Estado do Pará implementou o Fundef em 1997, dentro do período de carência negociado com alguns governadores (Souza, 2005, p.80). 
b. criou-se uma instância de formulação, debate e negociação federativa, a Comissão Intergovernamental de Financiamento para a Educação Básica de Qualidade, que incluiu a dimensão regional;

c. possibilitou-se a setorização da lei complementar para disciplinar a cooperação entre os entes federados na esfera educacional, que passa a ser um dos desafios da agenda para a consolidação do Fundeb.

No aspecto do controle social, as fragilidades reveladas no período do Fundef levaram ao aperfeiçoamento das regras referentes aos conselhos, acerca de sua autonomia, democracia, composição e instrumentos. Também em relação ao controle exercido pelo Ministério Público, como "fiscal da lei", possibilitou-se o litisconsórcio entre o federal e os estaduais, isto é, a reunião de interessados num mesmo processo, de forma a tornar mais eficaz a fiscalização no caso dos fundos que receberem complementação da União.

Ao lado desses avanços, a legislação trouxe um cenário diferente daquele do Fundef, que era expressamente reservado ao ensino público, ao admitir a inclusão de matrículas das instituições privadas conveniadas que atuam na educação infantil e especial. Torna-se, dessa forma, necessário criar novos mecanismos de acompanhamento e controle para garantir a transparência, além de ser necessário o debate acerca do ritmo de expansão das matrículas das instituições conveniadas em relação às públicas.

Finalmente, a legislação ainda não resolve o problema do custo-alunoqualidade. Ao contrário, traz dois elementos perturbadores:

a. ao deslocar um elemento do mecanismo de financiamento voltado para a eqüidade (valor mínimo por aluno) para atender ao objetivo da qualidade, com a possibilidade de que parte dos recursos da complementação da União ( I 0\%) sejam aplicados em programas de qualidade, permite a redução do valor mínimo para alguns entes;

b. ao permitir que a aplicação dos recursos se dê indistintamente entre etapas e modalidades de ensino e tipos de estabelecimento, esvazia a lógica do custo: constroem-se parâmetros para a captação, mas o gasto é livre, em qualquer categoria.

grande desafio, neste aspecto, é tornar efetiva a disposição constitucional que prevê a garantia, pelos entes federados, do financiamento da 
educação básica e da melhoria da qualidade de ensino, de forma a garantir padrão mínimo definido nacionalmente (artigo 60, § $1^{\circ}$ do Ato das Disposições Constitucionais Transitórias - ADCT).

Por mais bem desenhada que seja uma política e concebida a respectiva legislação, por mais que se tenha debatido, no Executivo, no Legislativo e na sociedade civil, somente a experiência poderá revelar seus acertos e fragilidades. Particularmente, o período do gradualismo até a implantação plena do Fundeb pode dar indicações importantes para o aperfeiçoamento de sua legislação.

\section{FUNDEF E FUNDEB: SEMELHANÇAS E DIFERENÇAS}

O Fundeb adotou as seguintes características que já integravam o Fundef:

- natureza contábil do fundo;

- contas únicas e específicas com repasses automáticos;

- âmbito de cada estado, sem comunicação de recursos para além das fronteiras estaduais;

- aplicação de diferentes ponderações para etapas e modalidades de ensino e tipos de estabelecimento;

- controle social e acompanhamento exercido por conselhos nas três esferas federativas;

- destinação a ações de manutenção e desenvolvimento do ensino na educação básica (artigo 70 da Lei de Diretrizes e Bases da Educação Nacional - LDB);

- possibilidade de retificação dos dados do censo por demanda dos entes federados;

- complementação da União.

Entre os aspectos que representam aperfeiçoamento em relação ao Fundef podem-se mencionar:

- todas as etapas da educação básica passaram a contar com um mecanismo de financiamento (a inclusão das creches não estava prevista na proposição enviada pelo Poder Executivo e ocorreu com a ampla mobilização da comunidade educacional, particularmente do denomi- 
nado movimento Fraldas Pintadas e do compromisso assumido pelo Congresso Nacional);

- a regra da complementação da União, antes definida em legislação ordinária, e nunca respeitada pelos governos do período, foi constitucionalizada (no mínimo 10\% dos recursos dos fundos) e representa o maior avanço do novo modelo, vitória obtida no Congresso Nacional, que inclusive reconstituiu na lei regulamentadora o texto da EC n. 53/06, uma vez que a Medida Provisória - MP - n. 339/06 havia retirado a expressão "no mínimo";

- a vedação do uso da fonte do salário-educação para a complementação da União;

- a preocupação com o aperfeiçoamento do desenho institucional dos conselhos de acompanhamento e controle social, com base no aproveitamento de proposições elaboradas e aprovadas no âmbito da Câmara dos Deputados, ainda no período do Fundef (substitutivos ao Projeto de Lei n. 24I/99, do qual foram relatores os deputados Gastão Vieira, na Comissão de Educação, e Fátima Bezerra, na Comissão de Constituição, Justiça e Cidadania). Assim, foram criados impedimentos para que parentes de autoridades integrem os conselhos, foi reforçada sua autonomia, vedado o exercício da presidência por representante do órgão controlado e facultada, na esfera municipal, a transformação do conselho em câmara do conselho municipal de educação. Foram ainda expressamente previstas a indicação pelos sindicatos e a eleição pelos pares;

- possibilidade de litisconsórcio facultativo entre os Ministérios Públicos estaduais e o federal;

- previsão de que também os registros contábeis e demonstrativos referentes às despesas realizadas estejam permanentemente à disposição dos Conselhos de Acompanhamento e Controle Social - CACs - e dos órgãos de controle interno e externo;

- previsão da fixação em lei de piso salarial profissional nacional para o magistério;

2. A proposição - PL n. 7.43।/06 ao qual está apensa a proposta do Executivo, PL n. 619/07 - está em tramitação na Câmara dos Deputados. Na Comissão de Educação e Cultura - CEC - foi aprovado o substitutivo do deputado Severiano Alves. Em seguida, a Comissão de Trabalho, 
- cômputo das matrículas, para recebimento dos recursos do fundo, tendo como critério obrigatório o atendimento ao âmbito de atuação prioritária, isto é, à função própria (educação infantil e ensino fundamental, para os municípios, e ensino médio e ensino fundamental, para os estados);

- a exemplo da Lei que aprovou o PNE, a Lei do Fundeb prevê (artigo 30, VI) avaliações periódicas e um prazo para realização da primeira avaliação da lei (até 2008);

- previsão da realização, no prazo de cinco anos, de fórum nacional com o objetivo de avaliar o financiamento da educação básica, com representantes das esferas federativas, trabalhadores, pais e alunos (artigo 35, Lei do Fundeb), além da garantia de participação popular e da comunidade educacional no processo de definição do padrão nacional de qualidade (artigo 38, parágrafo único);

- no plano conceitual, a consolidação da proposta de educação no campo como substitutivo à "escola rural".

Entre as inovações que constituem, a nosso ver, opções técnicas diferentes das adotadas no Fundef sem representar, a priori, avanço ou retrocesso, incluem-se:

- forma diferente de evitar a implantação abrupta: enquanto no Fundef optou-se por um prazo de carência de um ano até a implantação compulsória, no caso do Fundeb optou-se pelo gradualismo, com a inserção progressiva dos recursos oriundos dos impostos, que constituem fontes da cesta-Fundeb e das matrículas que constituem a base de cálculo para sua percepção;

- possibilidade de que a conta única e específica seja no Banco do Brasil ou na Caixa Econômica Federal, (nesse caso é importante verificar a partir da implantação, se a duplicação das instituições bancárias pode gerar algum tipo de desorganização administrativa ou se pode

Administração e Serviço Público, aprovou o parecer da relatora, deputada Andréia Zito, favorável ao Substitutivo da CEC, com emendas. A matéria está em análise na Comissão de Finanças e Tributação. 
contribuir para a negociação pelos entes federados de custos de administração bancária).

Como repetição dos temores dos arquitetos do Fundef, o Fundeb, embora tenha aumentado o prazo de vigência para I 4 anos (até 2020), também não ousou trazer as regras de financiamento para o corpo permanente da Constituição, mantidas nas Disposições Transitórias. Ressalte-se, contudo, que a incorporação total das matrículas e dos recursos do Fundef ocorrerá após um ano e ocorrerá em três anos no caso do Fundeb.

Finalmente, há aspectos problemáticos, que merecem um acompanhamento de perto ao longo da vigência do fundo.

O Fundef era um fundo destinado exclusivamente ao ensino fundamental público, ao passo que o Fundeb incorpora, na educação infantil e na educação especial, matrículas da rede privada conveniada. Embora seja um aspecto que necessariamente merecia ser considerado por um período de transição, à exceção das pré-escolas, o ingresso das matrículas privadas passa a ser constante até o fim do prazo de vigência do fundo.

Com o Fundeb sinaliza-se a construção do financiamento em uma perspectiva de custo: são ampliadas as categorias etapas, modalidades, tipos de estabelecimento, incluindo a jornada, sobre as quais incidem as ponderações. Há mesmo, a exemplo do que havia no Fundef, mas não se cumpriu, uma abertura na direção do custo-aluno-qualidade. A Lei do Fundeb prevê que as ponderações, que podem flutuar numa banda de 0,7 a I,3, respeitadas as pontuações mínimas previstas em seu artigo $36, \S 2^{\circ}$, sejam fixadas com base em estudos de custo realizados pelo Instituto Nacional de Estudos e Pesquisas Educacionais - Inep (artigo 13, I). Entretanto, essa sinalização naufraga e se frustra com a regra do artigo 2 I, da Lei n. I 1.494/07, Lei do Fundeb, que prevê a aplicação indistinta. As ponderações são elementos para a captação de recursos, mas, segundo esse dispositivo, o gasto é livre, isto é, pode-se captar por uma etapa ou modalidade e gastar em outra. Mais do que isso, pode-se, no limite, captar determinado valor pela matrícula pública e aplicá-la na conveniada, e vice-versa. As ponderações podem até orientar, mas não vinculam os gastos. Esse dispositivo, aliás, torna totalmente inócua a regra do artigo $8^{\circ}$, $\S 5^{\circ}$, da referida lei, o qual prevê que as eventuais diferenças de valor por aluno/ano entre instituições públicas e privadas sejam aplicadas na infra-estrutura da rede pública. 
O fato foi notado por Oliveira (2007, p.20), que, preocupado com o financiamento do ensino médio, conclui que, apesar de esta etapa ter contado em 2007 com fatores de ponderação maiores, "isso não significa dizer que os recursos projetados para o ensino médio não possam ser aplicados em outros níveis de ensino".

A EC n. 53/06 permite a dedução de recursos da complementação para a aplicação em programas de melhoria da qualidade. Ora, a complementação é efetuada para aqueles que não atingiram o valor mínimo. Não convém misturar um mecanismo que foi construído com o objetivo da eqüidade e sacrificá-lo em nome da qualidade, que deve ser fortalecida por outros mecanismos de financiamento, como os impostos que não constam da cesta-Fundeb, o salário-educação e os recursos do Plano de Desenvolvimento da Educação - PDE. Para Souza Jr. (2007, p.6), a medida representa um retrocesso, uma vez que significa "diminuir os recursos diretamente repassados para estados e municípios para a valorização do magistério e demais investimentos diretos na educação básica".

QUADRO I

IMPOSTOS QUE INTEGRAM A CESTA-FUNDEB (E RESPECTIVAS DÍVIDAS ATIVAS, JUROS E MULTAS), NO PATAMAR DE 20\%

\begin{tabular}{|c|c|c|}
\hline Esfera & Impostos & Transferências \\
\hline \multirow{3}{*}{ Estados/DF } & IPVA & FPE \\
& ITCM & IPI Exp. \\
& ICMS & Compensação - desoneração - \\
& Lei Kandir \\
\hline \multirow{2}{*}{ Municípios } & Da União \\
& FPM \\
& ITR (50\%)* \\
\cline { 2 - 3 } & Do Estado \\
& IPVA (50\%) \\
& ICMS (25\%) \\
& IPI-Exp. \\
\hline
\end{tabular}

* A Lei n. 1 I.250/05 permite que os municípios e o DF celebrem convênio com a Secretaria da Receita Federal, para se responsabilizar pela arrecadação e fiscalização do imposto. Neste caso, a totalidade dos recursos passa a pertencer aos municípios. 
QUADRO 2

IMPOSTOS QUE NÃO INTEGRAM A CESTA-FUNDEB

\begin{tabular}{|c|c|c|}
\hline Esfera & Impostos & Transferências \\
\hline Estados/DF & & $\begin{array}{c}\text { Da União } \\
\text { IRRF }\end{array}$ \\
\hline & & Da União \\
Municípios & IPTU & IRRF \\
& ITBI & \\
\hline
\end{tabular}

Toledo Jr. (2007) aponta ainda a polêmica em torno do $\S 2^{\circ}$ do artigo 21 da Lei do Fundeb, que permite que $5 \%$ dos recursos recebidos na conta do fundo sejam utilizados no exercício imediatamente subseqüente. $O$ autor vê neste dispositivo uma retomada da antiga lei regulamentadora da Emenda Calmon (Lei n. 7.348/85), constituindo retrocesso em relação ao texto do artigo $69, \S 4^{\circ}$ da LDB. Participamos da preocupação, mas não desta interpretação. De fato, a redação do dispositivo não é a melhor. Entretanto, este deve ser lido em conjunto com a regra da LDB, configurando-se em regra de transição apenas para o último trimestre do exercício, sem que os entes estejam dispensados de fazer o ajuste trimestral previsto na LDB, em relação aos três primeiros trimestres. Ademais, a Lei do Fundeb, ao contrário da antiga lei regulamentadora da Emenda Calmon, cria o limite de $5 \%$ dos recursos recebidos à conta do fundo, e não $5 \%$ dos $25 \%$, o que corresponderia a um quinto do valor. De qualquer forma, é importante esclarecer a interpretação que será adotada.

\section{PAPEL E COMPLEMENTAÇÃO DA UNIÃO}

A exemplo do Fundef, a complementação da União ao Fundeb será efetuada sempre que, no âmbito de cada estado ou do Distrito Federal, o valor por aluno não alcançar o mínimo definido nacionalmente. No caso do Fundef, a legislação ordinária previa a regra (artigo 6, caput e $\S 1^{\circ}$ da Lei n. 9.424/96) da média nacional obtida pela divisão da estimativa de receitas pelo número de matrículas, dispositivo que, infelizmente, não foi cumprido em todo período do Fundef. Com o advento do Fundeb, mudou-se o critério para o de "esforço federativo" (Martins, 2005, p.45-47). Assim, define-se primeiro o valor da complementação da União e, a partir deste, o valor mínimo por aluno/ano. 
A proposta do Executivo indicava valores fixos para a complementação. Estes foram ampliados pelo Legislativo, que ainda determinou que tais valores fossem "mínimos" (expressão da EC n. 53/06, retirada inconstitucionalmente pela MP n. 339/06 e Lei do Fundeb). Os valores previstos, a serem anualmente corrigidos pelo Índice Nacional de Preços ao Consumidor - INPC -, são de, no mínimo:

$1^{\circ}$ ano (2007) -2 bilhões de reais

$2^{\circ}$ ano $(2008)-3$ bilhões de reais

$3^{\circ}$ ano $(2009)-4,5$ bilhões de reais

a partir do $4^{\circ}$ ano $(2010)$ - $10 \%$ do valor do fundo.

Trata-se de questão que inegavelmente constitui um importante avanço. O Projeto do Plano Plurianual - 2008-20 I I prevê a complementação da União, que alcançará os fundos das regiões Norte e Nordeste, segundo a tabela I.

TABELA I

COMPLEMENTAÇÃO DA UNIÃO AO FUNDEB NO PPA 2008-20I I (EM REAIS)

\begin{tabular}{c|c|c|c|c}
\hline Ano & 2008 & 2009 & 2010 & 2011 \\
\hline Nordeste & 2.452 .423 .695 & 3.820 .775 .486 & 5.945 .160 .958 & 6.515 .821 .570 \\
\hline Norte & 684.807 .285 & 1.080 .224 .513 & 1.680 .893 .041 & 1.842 .178 .430 \\
\hline Total & 3.137 .230 .980 & 4.900 .999 .999 & 7.625 .999 .999 & 8.358 .000 .000 \\
\hline
\end{tabular}

Fonte PL n. 31/2007 - CN-PPA.

Em relação à complementação há, ainda, duas disposições importantes:

- vedação do uso dos recursos do salário-educação como fonte da complementação (sua utilização passa, inclusive, a caracterizar crime de responsabilidade);

- utilização dos recursos da manutenção e desenvolvimento do ensino federal até, no máximo, 30\% da complementação da União. Esta proteção à fonte típica de financiamento da educação implica o uso de outras fontes como garantia para que se efetive a complementação, cujo desrespeito também constitui crime de responsabilidade, e contribui para evitar a disputa fratricida entre educação básica e superior. 
Como mencionamos, permite-se que sejam utilizados até 10\% dos recursos da complementação da União em programas de qualidade. Em primeiro lugar, cumpre esclarecer que a parcela da complementação conserva a natureza desta e, portanto, somente pode ser distribuída aos fundos no âmbito dos estados que receberem a complementação da União. Esse dado é importante, porque um dos possíveis motivos da inserção da medida foi a expectativa de estados, que não recebem a complementação, atraírem alguns recursos federais por esta via. Isso é absolutamente inconstitucional. Ainda que a lei procure estabelecer critérios razoáveis tais como projetos em regime de colaboração, consórcios municipais, esforço de habilitação de professores, esforço fiscal e vigência de plano de educação, que até poderiam ser aproveitados no Plano de Desenvolvimento da Educação, a utilização de recursos da complementação, desenhados para atender, na dimensão da eqüidade, os fundos com recursos abaixo do valor mínimo estabelecido, não nos parece adequada. Rebaixa o valor estabelecido como mínimo.

Castro e Duarte (2007, p. 14) calcularam as despesas educacionais de cada esfera federativa entre 1995 e 2005, aí incluídas as despesas com o ensino superior.

TABELA 2

DESPESAS DA UNIÃO COM EDUCAÇÃO I 995-2005 (EM MILHÕES DE REAIS)

\begin{tabular}{c|c|c}
\hline Anos & Valores constantes & Participação percentual no esforço federativo \\
\hline 1995 & $14.605,3$ & 23,8 \\
\hline 1996 & $12.683,4$ & 20,4 \\
\hline 1997 & $12.197,3$ & 20,4 \\
\hline 1998 & $13.194,3$ & 19,2 \\
\hline 1999 & $13.464,4$ & 19,2 \\
\hline 2000 & $15.553,3$ & 21,8 \\
\hline 2001 & $15.263,6$ & 20,3 \\
\hline 2002 & $14.685,0$ & 18,7 \\
\hline 2003 & $13.764,3$ & 17,9 \\
\hline 2004 & $15.221,8$ & 18,2 \\
\hline 2005 & $16.614,4$ & 19,1 \\
\hline
\end{tabular}

Fonte: a partir de Castro e Duarte, 2007.

Com base nos dados apresentados pelos autores pode-se chegar a algumas conclusões importantes: 
- houve, em valores constantes, uma ampliação do gasto total realizado pelas três esferas de governo;

- o gasto nominal da União caiu de 1995 a 1997, teve uma pequena recuperação em 1998 e 1999, aumentou em 2000 e 200 I, voltou a cair em 2002 e 2003 e vem se recuperando a partir de 2004;

- em termos relativos, entretanto, a participação da União teve uma queda constante até 1999, uma recuperação em 2000, nova tendência declinante de 200 I a 2003 e uma recuperação a partir daí. Entretanto ficou, em 2005, no mesmo patamar do biênio 98/99, momento de implementação do Fundef.

Dessa forma, a "desresponsabilização da União" não pode ser indicada e avaliada no vazio, isoladamente, já que, em valores constantes, houve aumento, mas, em face do pacto federativo, percebe-se nitidamente o comportamento incrementalista ("inercial") do orçamento da educação, com pequenas variações, sendo que os percentuais foram rigorosamente os mesmos nos biênios de 96/97 e 98/99. A regra para a complementação da União no Fundeb deve sustentar a recuperação de sua participação percentual, mas é preciso verificar em que patamar será estabilizada. Assim, dado que os valores da complementação da União são valores mínimos, parece-nos que a reivindicação mais imediata que o setor educacional deve fazer é, ao menos, a retomada do patamar de participação da União nas despesas educacionais, em termos percentuais, em face da contribuição dos demais entes federados, em 1995 (em torno de $24 \%$ das despesas).

\section{GARANTIA DO VALOR MÍNIMO PARA O ENSINO FUNDAMENTAL}

A prioridade ao ensino fundamental foi estabelecida pelo constituinte em 1988. Não é fruto da EC n. I 4/96. É no texto original da Constituição Federal que estão contidas as determinações segundo as quais:

- o ensino fundamental é obrigatório (artigo 208, I);

- o acesso ao ensino obrigatório e gratuito é direito público subjetivo (artigo 208, § ${ }^{\circ}$ );

- a distribuição de recursos públicos assegurará prioridade ao atendimento das necessidades do ensino obrigatório (artigo 212, §3). 
A EC n. 53/06 não alterou esses critérios. Não houve debate acerca da extensão da duração do ensino obrigatório. Na Argentina, o último ano da educação infantil é obrigatório. No Chile, a obrigatoriedade se estende ao nível médio. A possibilidade de se tornar toda a educação básica direito público subjetivo chegou a ser timidamente levantada nos debates da Câmara dos Deputados, mas não foi adotada qualquer mudança ${ }^{3}$. A EC n. 53/06, de certa forma, até radicalizou num aspecto: criou regra, com status constitucional e no corpo permanente da Constituição, acerca do atendimento prioritário, pela educação básica pública, do ensino regular (artigo 212, §5). A interpretação acerca do alcance desta expressão também é problemática. Nos debates no Legislativo era freqüentemente utilizada em contraste com a Educação de Jovens e Adultos - EJA. Entretanto, há textos que diferenciam o ensino regular da educação a distância e, finalmente, há quem entenda que o termo se opõe a qualquer modalidade de ensino.

De forma coerente com a manutenção da prioridade ao ensino fundamental obrigatório, a Emenda do Fundeb (EC n. 53/06) criou uma proteção ao valor mínimo praticado no ensino fundamental. A redação do $\S 2^{\circ}$ do artigo 60 do Ato das Disposições Constitucionais Transitórias, dada pela EC n. 53/06, prevê que este não poderá ser inferior ao praticado no último ano do Fundef. Observe-se, ainda, que o valor referido será corrigido anualmente pelo INPC ${ }^{4}$.

\section{A COMISSÃO INTERGOVERNAMENTAL: PONDERAÇÕES E TRAVAS}

A Comissão Intergovernamental de Financiamento para a Educação Básica de Qualidade originou-se da “junta de acompanhamento", prevista na MP

3. O tema foi levantado em duas ocasiões. A primeira, em audiência pública a que compareceu a pesquisadora Ângela Barreto, do Instituto de Pesquisa Econômica Aplicada - Ipea -, que fez distribuir cópia da decisão do Supremo Tribunal Federal, que teve como relator o ministro Celso Mello, acerca do atendimento em creche e pré-escola como dever constitucional do poder público (Resolução 43.6996/SP - decisão de 26/l 0/05, publicada no Diário da Justiça da União de 7/I I/05). A segunda, em reunião informal acerca do custo-aluno-qualidade.

4. Em 2007, somente nos estados de Roraima e Tocantins o valor por aluno/ano para o ensino fundamental do Fundeb foi, inicialmente, menor que o praticado no Fundef, tendo sido ajustado conforme a legislação. Com o crescimento da arrecadação, a tendência é que o valor do Fundeb supere o último valor do Fundef. 
n. 339/06, que fixou as ponderações para as etapas, modalidades e tipos de estabelecimento da educação básica para efeito de recebimento dos recursos do Fundeb, vigentes para 2007. A nova composição da comissão ampliou aquela prevista na junta de acompanhamento e criou um espaço de debate e negociação federativos no qual é reconhecida a pluralidade de perspectivas e interesses não só de entes da mesma natureza, mas também das diferentes regiões. A comissão é composta por onze membros:

- um representante do MEC;

- um representante estadual, de cada uma das cinco regiões políticoadministrativas brasileiras, indicado pelas seccionais do Conselho Nacional de Secretários de Educação - Consed;

- um representante municipal, de cada uma das cinco regiões políticoadministrativas brasileiras, indicado pelas seccionais da União Nacional dos Dirigentes Municipais de Educação - Undime.

São atribuições da comissão:

a. fixação anual das ponderações aplicáveis a etapas, modalidades e tipos de estabelecimento para distribuição proporcional dos recursos, respeitados os patamares mínimos definidos para a educação infantil e levada em consideração sua correspondência com o respectivo custo real, segundo estudos do Inep;

b. fixação anual do limite proporcional de apropriação de recursos pelas diferentes etapas, modalidades e tipos de estabelecimento de ensino da educação básica. Trata-se das chamadas "travas". O mandamento constitucional refere-se a todas as categorias. Entretanto a lei fixou

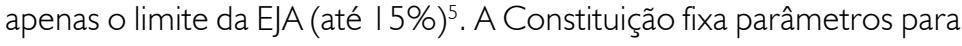
esta definição: os artigos 208 e 214 da Constituição Federal e as metas do Plano Nacional de Educação. Está subjacente uma idéia de gradação na priorização. Assim, o ensino fundamental é obrigatório, o médio

5. Este percentual foi definido quando o projeto voltou à Câmara. Havia sido reduzido para I0\% por meio de aprovação de emenda no plenário quando da primeira votação na Câmara, percentual que fora mantido no Senado. Na realidade, há margem ampla: a apropriação atual de recursos pela modalidade chega, no máximo, a 5, 1 \%, no Estado do Acre. 
requer progressiva universalização e, no caso da educação infantil, deve-se proceder ao atendimento. No que se refere ao PNE, a meta de atendimento do ensino médio ao fim de dez anos é de $100 \%$ da demanda ${ }^{6}$ enquanto a da educação infantil é a de atender a $50 \%$ das crianças de até 3 anos e $80 \%$ das de 4 e 5 anos. $O$ dispositivo suscita outra antinomia normativa, em que a norma infraconstitucional que fixou a "trava" da EJA parece entrar em contradição com o parâmetro constitucional, que, ao remeter ao artigo 2 । 4, não pode ignorar que este prevê como objetivo a erradicação do analfabetismo. Como, então, a EJA é a única categoria a ser limitada?

c. fixação anual da parcela da complementação da União (até o limite de 10\%) a ser distribuída pelos fundos por meio de programas direcionados para a melhoria da qualidade da educação básica e respectivos critérios de distribuição;

d. elaboração, requisição e orientação de estudos técnicos;

e. elaboração de seu regimento interno.

Conforme dispõe a Lei do Fundeb (artigo 12, §2), a Comissão deve fixar as ponderações em resolução publicada no Diário Oficial da União, até o dia 3 I de julho de cada exercício. Em 2007, este prazo não foi atendido e a decisão ainda não havia sido tomada quando da elaboração deste texto.

\section{TRANSPARÊNCIA, CONTROLE E PAPEL DOS CONSELHOS DE ACOMPANHAMENTO E CONTROLE SOCIAL}

O acompanhamento e controle social são efetuados por conselhos, a exemplo do Fundef. Foram criadas regras, a partir de proposições elaboradas na Câmara dos Deputados, consolidadas nos Substitutivos dos deputados Gastão Vieira e Fátima Bezerra, e de propostas apresentadas quando da tramitação da MP n. 339/06, para tornar os Conselhos de Acompanhamento e Controle Social - CACs - mais efetivos, no que se refere a:

6. A palavra aqui é ambígua: demanda não é necessariamente a totalidade da faixa considerada como idade própria - pode ser demanda efetiva (quem procura), demanda potencial (totalidade da faixa etária) ou induzida (com crescimento a partir de meta definida). 


\section{Impedimentos:}

a. cônjuges e parentes consangüíneos ou afins até $03^{\circ}$ grau dos dirigentes dos poderes públicos;

b. tesoureiros, contadores ou funcionários de empresa de assessoria ou consultoria que prestem serviços relacionados à administração ou controle interno dos recursos do fundo e respectivos parentes;

c. estudantes não emancipados;

d. pais de alunos que exerçam cargos ou funções de livre nomeação ou prestem serviços terceirizados no âmbito dos poderes públicos em que atuarem;

2. Indicação do Presidente: escolhido pelos pares, não podendo ser o representante do governo gestor dos recursos;

3. Autonomia: os CACs não têm vinculação ou subordinação institucional ao poder executivo local;

4. Renovação periódica: ao final do mandato de seus membros. Os mandatos serão de até 2 anos, permitida uma recondução por igual período;

\section{Garantias aos conselheiros:}

a. isenção de obrigatoriedade de testemunhar sobre informações recebidas ou prestadas em razão do exercício de suas atividades e sobre pessoas que lhes confiaram as informações - artigo $24, \S 8^{\circ}$, III;

b. vedação de exoneração ou demissão sem justa causa ou transferência involuntária de professores, diretores e servidores - artigo 24, §8॰, IV, "a";

c. vedação de atribuição de falta injustificada em função das atividades do conselho - artigo 24, §8॰ , IV, "b";

d. afastamento involuntário da condição de conselheiro - artigo 24, $\S 8^{\circ}, \mathrm{IV}$, " c";

e. vedação de atribuição de falta injustificada às atividades escolares, em função das atividades do conselho, quando os conselheiros forem estudantes - artigo $24, \S 8^{\circ}, \mathrm{V}$.

Quanto à composição dos conselhos, houve ligeira modificação no Congresso em relação à proposta do Executivo, passando a ser a seguinte: 
- CACs Federal: no mínimo, 14 membros, com representação de: MEC - 4; Fazenda - 1; Planejamento - I; Conselho Nacional de Educação - I; Consed - I; Undime - I; Confederação Nacional dos Trabalhadores em Educação - I; Pais de alunos - 2; Estudantes - 2 (um indicado pela União Brasileira dos Estudantes Secundaristas);

- CACs Estadual: no mínimo, 12 membros, com representação de: Executivo estadual - 3; Executivos municipais - 2; Conselho Estadual de Educação - I; Undime - I; CNTE - I; Pais de alunos - 2; Estudantes - 2 (um indicado pela entidade secundarista);

- CACs do Distrito Federal: no mínimo, 9 membros, mesma composição dos CACs estaduais, excluídos os representantes da Undime e dos executivos municipais, uma vez que o DF não tem municípios;

- CACs Municipais: no mínimo, 9 membros com representação de: Poder Executivo municipal - 2 ( I da Secretaria de Educação); Professores da educação básica pública - I (indicado pela entidade sindical); Diretores das escolas públicas - I; Servidores técnico-administrativos - I (indicado pela entidade sindical); Pais de alunos - 2; Estudantes - 2 (um indicado pela entidade secundarista). A esta composição mínima adiciona-se, quando houver, representantes do Conselho Municipal de Educação (I) e do Conselho Tutelar (I).

São atribuições dos conselhos:

- exercer o acompanhamento e controle social sobre a distribuição, transferência e aplicação dos recursos;

- supervisionar o censo escolar anual e a elaboração da proposta orçamentária;

- elaborar parecer para instruir a prestação de contas - esta peça é obrigatória para apreciação da prestação.

Aos CACs incumbe, ainda, acompanhar a aplicação dos recursos federais transferidos à conta do Programa Nacional de Apoio ao Transporte do Escolar - PNATE - e do Programa de Apoio aos Sistemas de Ensino para Atendimento à Educação de Jovens e Adultos e, ainda, receber e analisar as prestações de contas referentes a esses programas, formulando pareceres 
conclusivos acerca da aplicação desses recursos e encaminhando-os ao Fundo Nacional de Desenvolvimento da Educação - FNDE. Observe-se que aos conselhos cabe, ainda, acompanhar os convênios com as instituições comunitárias, filantrópicas ou confessionais que sejam beneficiárias do Fundeb, uma vez que podem requisitar os documentos a eles pertinentes (artigo 25, § único, III, "c", Lei n. I I.494/07).

Entre os mecanismos à disposição dos conselhos para efetuar seu trabalho a lei prevê:

a. acesso permanente aos registros contábeis e demonstrativos gerenciais mensais, atualizados, relativos aos recursos repassados e recebidos e às despesas realizadas, sobre os quais podem apresentar manifestação formal ao Legislativo e órgãos de controle;

b. acesso permanente aos extratos bancários das contas do fundo, obrigatoriamente disponibilizados pelo Banco do Brasil ou pela Caixa Econômica Federal;

c. capacitação oferecida pelo MEC;

d. convocação do secretário de educação para prestar esclarecimento, que deverá apresentar em prazo não superior a 30 dias;

e. elaboração de parecer que instruirá as prestações de contas em relação aos recursos do Fundeb e de parecer conclusivo em relação ao PNATE e ao programa de apoio à EJA;

f. requisição de documentos (licitação, empenho, liquidação, pagamento, folhas de pagamento);

g. visitas e inspetorias in loco.

A Lei do Fundeb inova ao prever a possibilidade de que os conselhos de acompanhamento, no nível municipal, sejam integrados ao conselho municipal de educação, por meio de uma câmara específica, cuja competência será deliberativa e terminativa, isto é, não sujeita à reforma pelo "pleno" ou à homologação pelo executivo. Nesse caso, a lei procura introduzir uma "contaminação positiva” ao prever que os próprios conselhos de educação devem adotar, em sua composição, as regras dos conselhos do Fundeb no que se refere aos impedimentos. Parece-nos que, se a experiência é válida para o nível municipal, não há porque não permitir que ocorra nas demais esferas. 
Outra inovação importante consiste na admissão de litisconsórcio entre os ministérios públicos estaduais e da União, de forma a ampliar a capilaridade e a capacidade de controle.

O artigo 25 da Lei do Fundeb prevê que, além dos registros contábeis e demonstrativos gerenciais mensais relativos aos recursos repassados e recebidos dos fundos, também os referentes às despesas realizadas estejam permanentemente à disposição dos CACs e dos órgãos de controle interno e externo, e lhes seja dada ampla publicidade, inclusive por meio eletrônico. Há, como vimos, um aperfeiçoamento em relação ao dispositivo equivalente na Lei do Fundef, artigo $5^{\circ}$.

\section{DESTINAÇÃO DE RECURSOS ÀS ESCOLAS CONVENIADAS}

Antes da avaliação do mérito da inserção dessas instituições no universo do Fundeb, há um debate preliminar, de natureza constitucional. O artigo 60, II das Disposições Transitórias prevê a distribuição dos recursos entre estados e seus municípios, proporcionalmente ao número de alunos das diversas etapas e modalidades da educação básica presencial, matriculados nas respectivas redes. A redação é semelhante a dispositivo equivalente da EC n. I 4/96. Ocorre que, na ocasião, sempre se entendeu que "respectivas redes" implicava a delimitação das vagas públicas. Tanto assim que o relator da lei regulamentadora do Fundef rejeitou emenda com base neste argumento e a própria lei previa expressamente que os recursos eram destinados ao ensino fundamental público. Se prevalecesse o entendimento de que as vagas das instituições privadas estavam abrangidas, o mencionado dispositivo teria criado limitação não prevista na Constituição e a Lei do Fundef seria, neste aspecto, inconstitucional - o que jamais foi argüido em dez anos de vigência.

A idéia de uma transição somente foi admitida no caso das pré-escolas (por 4 anos). As instituições conveniadas que atuam na educação especial e as creches que atenderem aos requisitos previstos na Lei n. I I.494/07 passam a ser beneficiárias permanentes do Fundeb.

Para a inclusão de suas matrículas para efeito de recebimento de recursos do Fundeb, as instituições de educação especial, pré-escolas e creches conveniadas devem obedecer aos seguintes requisitos: 
a. oferta em igualdade de condições para o acesso e permanência na escola e atendimento educacional gratuito a todos os alunos;

b. ausência de fins lucrativos;

c. serem caracterizadas como instituições comunitárias, confessionais e filantrópicas;

d. assegurar a destinação de seu patrimônio a entidades congêneres em caso de encerramento de atividades;

e. atender a padrões mínimos de qualidade, definidos pelo órgão normativo do sistema de ensino, inclusive aprovação de seus projetos pedagógicos;

f. ter certificado do Conselho Nacional de Assistência Social ou órgão equivalente;

g. no caso das pré-escolas, pelo período de 4 anos;

h. no caso da educação especial, atuação exclusiva na modalidade.

Para Toledo Jr. (2007, p.7), os repasses às instituições devem, ainda, atender ao disposto no caput do artigo 26 da Lei Complementar n. I 0 I/2000 (Lei de Responsabilidade Fiscal), que prevê a autorização, por lei específica, do atendimento às condições estabelecidas na Lei de Diretrizes Orçamentárias e a previsão no orçamento.

\section{TRANSPORTE ESCOLAR}

As despesas com transporte escolar figuram entre aquelas previstas no artigo 70 da LDB, que constituem gastos com manutenção e desenvolvimento do ensino. Estados e municípios são, portanto, os principais responsáveis. Tratase de item, aliás, em que avultam as disputas federativas. Cabe frisar, ainda, que a função supletiva da União é particularmente importante. Esta dá-se a partir de dois programas: o PNATE, que repassa recursos para o transporte do aluno do ensino fundamental residente na zona rural, e o "caminho da escola", integrado ao PDE, que prevê empréstimos do BNDES em condições especiais para aquisição de veículos para o transporte escolar.

Os municípios freqüentemente transportam alunos da rede estadual sem obter os recursos correspondentes. Assim, representantes dessa esfera, sobretudo a Confederação Nacional de Municípios, tentaram inserir o trans- 
porte como elemento de distribuição dos recursos do Fundeb. A alternativa parece-nos inconstitucional, uma vez que o critério de distribuição refere-se expressamente às matrículas. Ademais, a dedução de recursos do Fundeb alteraria o valor por aluno. Diante da pressão, que teve grande repercussão no Congresso, foi inserido na Lei do Fundeb dispositivo que prevê a alocação, nos dois primeiros anos de vigência do Fundeb (2007 e 2008), de recursos orçamentários para o reforço do PNATE. Esse programa, entretanto, não é suficiente para solucionar os conflitos federativos entre estados e municípios.

Com a aprovação do Fundeb, é razoável que o PNATE seja estendido a toda a educação básica.

\section{CONCLUSÃO}

A legislação do Fundeb beneficiou-se da experiência do Fundef. Manteve alguns de seus aspectos e inovou em outros. Entre os avanços concretos quanto à situação anterior podem-se destacar: um equacionamento razoável da questão da complementação da União (considerando-se que os valores são mínimos e podem e devem ser ampliados até, ao menos, o patamar de gastos praticado pela União em 1995) e a aposta num espaço federativo de negociação como a Comissão Intergovernamental de Financiamento para a Educação Básica de Qualidade. Além disso, impulsionou a definição de piso salarial para o magistério.

No entanto, foram criados novos problemas, como a aplicação dos recursos indistintamente, o que se choca com a tentativa de organizar o financiamento a partir dos custos, e a inclusão das matrículas privadas da educação especial e das creches de forma permanente, para além de um prazo de transição. Cabe verificar a opção dos gestores acerca de qual será a estratégia para a expansão das vagas nas creches, se pelo setor público ou pela via da celebração de convênios. Os dados preliminares do censo escolar de 2007 indicam que o crescimento das matrículas das creches foi mais acentuado no setor público. Afasta-se, por ora, o risco de um crescimento predominantemente pela via das instituições privadas. Entretanto, a experiência do Fundef mostrou que a fase de acomodação das ações dos gestores, inclusive a "reclassificação estatística", perdurou por todo período de transição. Essa tendência deve-se reproduzir no caso do Fundeb. 
A Lei do Fundeb (artigo 30, $\mathrm{VI}$ ) adota dispositivo semelhante ao inaugurado pela Lei n. I0. I 72/0 I, que aprovou o PNE (artigo $3^{\circ}, \S 2^{\circ}$, PNE), no sentido de que seja feita avaliação com vistas à aprovação de medidas corretivas para aperfeiçoar o instrumento legal. A primeira avaliação deve ser feita pelo MEC até 2008, ano em que se realizará a Conferência Nacional de Educação Básica. Esses processos poderão contribuir para o aperfeiçoamento da legislação sobre o financiamento da educação, que deve abranger conjuntamente os recursos do Fundeb, do salário-educação e do PDE.

\section{REFERÊNCIAS BIBLIOGRÁFICAS}

BRASIL. Governo. Plano nacional de educação. Brasília: Câmara dos Deputados, 2002.

CASTRO, J. A.; DUARTE, B. Descentralização da educação pública no Brasil: evolução dos gastos e matrículas. Disponível em: http://www.anped.org.br. Acesso em: 29 out. 2007.

MARTINS, P. S. Financiamento da educação básica: critérios, conceitos e diretrizes. In: LIMA, M. J.; ALMEIDA, M. R.; DIDONET, V. (orgs.) Fundeb: dilemas e perspectivas. Brasília: Ediçãa independente, 2005, p.37-52.

OLIVEIRA, R. Os Limites do Fundeb no financiamento do ensino médio. Disponível em: http://www.anpocs.org.br. Acesso em: 29 out.2007.

SOUZA JR., L. Fundeb: novo fundo, velhos problemas. Disponível em: http://www.anped. org.br. Acesso em: 29 out.2007.

SOUZA, P. R. A Revolução gerenciada: educação no Brasil 1995-2002. São Paulo: Prentice Hall, 2005.

TOLEDO JR., F. C. O. Fundeb e o novo modelo de financiamento educacional. Disponível em: http://www.tce.sp.gov.br. Acesso em: 29 out. 2007

Recebido em: dezembro 2007

Aprovado para publicação em: janeiro 2008 